\title{
EFEITO DE DIFERENTES TRATAMENTOS TÉRMICOS SOBRE MICROESTRUTURA E MICRODUREZA DE UM SISTEMA AÇO C-Mn/REVESTIMENTO DE INCONEL 625
}

\author{
Vicente Braz Trindade \\ Edilberto da Silva Souza ${ }^{2}$ \\ Jorge Magalhães Alves de Paula ' \\ Maria Celeste Monteiro de Souza Costa ${ }^{2}$ \\ Geraldo Lúcio de Faria '
}

\section{Resumo}

A utilização de tubos de aço C-Mn na indústria de óleo e gás é muito comum desde o nascimento desta indústria. Mesmo com a grande evolução da metalurgia destes aços ao longo das últimas décadas, o desafio de desempenho em ambientes severos de corrosão devido às características reativas $\left(\mathrm{H}_{2} \mathrm{~S}, \mathrm{CO}_{2}\right)$ do petróleo e seus derivados, impõem uma nova era para a fabricação de tubos. A solução tecnológica mais direta seria a utilização de aços com alta liga $(\mathrm{Ni}, \mathrm{Cr})$ e/ou superligas de níquel. No entanto, os custos de produção tornariam inviáveis pelo alto custo destes materiais. Neste contexto, é crescente iniciativas de pesquisas para o desenvolvimento de overlay e/ou cladding, ou seja, revestimentos de aços C-Mn usando superligas de níquel e aços inoxidáveis. Neste trabalho, foi utilizada a deposição de uma camada da superliga de níquel Inconel 625 através do processo laser. Uma das desvantagens da deposição a laser ou qualquer outro processo de fusão é a formação de uma região de descontinuidade microestrutural no aço, chamada de ZTA (zona termicamente afetada pelo calor). Neste estudo, diferentes rotas de tratamentos térmicos foram investigadas com o objetivo de eliminar a ZTA e preservar as características originais do substrato e do revestimento.

Palavras-chave: Revestimento inconel 625/aço C-Mn; Perfil de microdureza; Transformação de fase; Martensita revenida; ZTA; Tratamentos térmicos.

\section{EFFECT OF DIFFERENT HEAT TREATMENTS ON MICROSTRUCTURE AND MICROHARDNESS OF A C-Mn STEEL/INCONEL 625 COATING SYSTEM}

\begin{abstract}
The application of C-Mn steel pipe in the oil \& gas industry is quite common since starting of this industry. Even with the great evolution of the metallurgy of this type of steel over the last decades, the challenge is to overcome the corrosion severity caused by sour $\left(\mathrm{H}_{2} \mathrm{~S}, \mathrm{CO}_{2}\right)$ species present in the petroleum and its derivates. The direct technological solution would be to replace the C-Mn steel by Ni-based superalloys and/or stainless steels. However, the high costs of these materials would make several projects impracticable. In this context, there are several initiatives in order to develop overlay and/or cladding, that means, coatings of C-Mn steels using superalloys and stainless steels. In this work, it was used an overlay deposition of Inconel 625 on the surface of a C-Mn steel using the laser process. A disadvantage of laser deposition, as it is for any deposition melting process, is the formation of a microstructural discontinuity in the steel substrate caused by the thermal cycle (HAZ = heat affected zone). In this study, different heat treatment routes were investigated aiming to eliminate the HAZ preserving the original characteristics of the substrate and of the coating.

Keywords: Inconel 625 overlay/C-Mn steel; Microhardness profile; Phase transformation; Tempered martensite; HAZ; Heat treatments.
\end{abstract}

'Universidade Federal de Ouro Preto - UFOP, Ouro Preto, MG, Brasil.E-mail: vicentebraz@yahoo.com.br

${ }^{2}$ Centro Federal de Educação Tecnológica de Minas Gerais - CEFET-MG, Belo Horizonte, MG, Brasil.

2176-1523 (C) 2016 Associação Brasileira de Metalurgia, Materiais e Mineração. Publicado pela ABM. Este é um artigo de acesso aberto distribuído sob os termos da licença Creative Commons CC BY-NC-ND (Attribution-NonCommercial-NoDerivs) - https:// creativecommons.org/licenses/by-nc-nd/4.0\%. 


\section{INTRODUÇÃO}

$\mathrm{Na}$ indústria de petróleo, a utilização de tubos é mandatória em várias partes do projeto para produção de óleo e gás. A classe de material mais utilizada na fabricação de tubos é aço C-Mn. No entanto, a crescente demanda por perfuração de poços cada vez mais profundos e a presença de agentes corrosivos como $\mathrm{H}_{2} \mathrm{~S}, \mathrm{CO}_{2}$ e cloretos [I] requerem materiais mais nobres do que os aços C-Mn [2-5]. Por isto, torna-se necessária a utilização de materiais mais nobres como aços austeníticos e ligas de níquel.

Por outro lado, a utilização destes materiais como tubos pode inviabilizar o projeto devido ao alto custo relacionado à matéria-prima e aos processos de fabricação. Por isto, é crescente $o$ estudo da utilização destes materiais nobres como revestimento de aços C-Mn. É bem conhecido e apresentado na literatura o bom desempenho de superligas de níquel, como Inconel 625, em ambientes corrosivos [6-13].

Uma das maneiras usadas para depositar ligas de níquel em substrato de aço é o processo chamado de "overlay" que usa a técnica de fusão através de arco elétrico ou laser. A literatura descreve que uma consequência destes processos é a formação de uma zona afetada pelo calor (ZTA) no substrato próximo à poça de fusão. A ZTA é definida como uma região com propriedades e microestruturas diferentes do substrato e do metal fundido [14]. A presença de uma ZTA pode ser deletéria para várias aplicações industriais, como por exemplo, estruturas sujeitas a fadiga, fragilização pelo hidrogênio em presença de $\mathrm{H}_{2} \mathrm{~S}$, dentre outras desvantagens.

Neste contexto, o objetivo deste trabalho é estudar o efeito de diferentes tratamentos térmicos na microestrutura e microdureza do sistema aço C-Mn/revestimento de Inconel 625 depositado a laser, bem como, avaliar o efeito de tratamentos térmicos capazes de eliminar esta ZTA e seus efeitos deletérios para o material.

\section{MATERIAIS E MÉTODOS}

Como substrato, utilizou-se neste estudo um aço C-Mn usado na indústria de óleo e gás como tubo para revestimento de poços de exploração. Antes da deposição do revestimento $\mathrm{o}$ aço foi temperado e revenido objetivando-se atingir o grau L80 tipo I de acordo com a norma API 5CT [15] A composição química do aço está apresentada na Tabela $I$.

Buscando caracterizar a temperabilidade deste aço, um ensaio de temperabilidade Jominy com corpo de prova subsize $(6,6 \mathrm{~mm}$ de diâmetro e $10 \mathrm{I} \mathrm{mm} \mathrm{de} \mathrm{comprimento)} \mathrm{foi}$ realizado. Um corpo de prova foi austenitizado a $900^{\circ} \mathrm{Ce}$ resfriado em aparelho Jominy padronizado. Medidas de dureza na escala HRc foram realizadas nas duas faces retificadas do corpo de prova e as médias dos valores obtidos ponto a ponto, como uma função da distância da superfície temperada, foram registradas.

O revestimento de inconel 625 foi depositado utilizando o processo de fusão a laser. Os parâmetros utilizados foram: velocidade de $240 \mathrm{~mm} / \mathrm{min}$; potência de $10 \mathrm{~kW}$; alimentação de $100 \%$ e lente $1 / 36$. A liga utilizada foi a inconel 625 , adicionada em forma de pó. A composição química da liga utilizada é apresentada na Tabela 2.

Pequenos corpos de prova foram confeccionados, por meio de procedimentos de corte refrigerado com disco de diamante para o estudo do efeito de alguns tratamentos térmicos sobre a microestrutura e perfis de microdureza da interface aço/inconel.

Diferentes rotas de tratamentos térmicos foram utilizadas na tentativa de representar possíveis rotas industriais, incluindo possíveis avarias durante tratamento térmico, como por exemplo, parada de peças nos fornos de tratamentos térmicos na linha industrial. A Figura I mostra esquematicamente as cinco rotas de tratamentos térmicos utilizadas. $O$ tratamento térmico I (TT_I) representa uma rota convencional utilizada na indústria de fabricação de tubos, já os tratamentos TT_2 e TT_3 simulam possíveis avarias que geralmente ocorrem no processo de tratamento térmico em um ambiente industrial. $\mathrm{O}$ tratamento TT_2, por exemplo, simula uma possível parada da linha por questões técnicas e o tempo de residência da amostra nas etapas de austenitização e revenimento podem ser muito prolongados. Neste caso, simulou-se intervalos de tempo de 480 e 960 minutos, respectivamente, nas etapas de austenitização e revenimento. O Tratamento TT_3 simula uma falha no forno, ou no sistema de resfriamento, por exemplo, e a amostra é resfriada lentamente até a etapa de revenimento.

Os tratamentos TT_4 e TT_5 são rotas em potencial para implantação neste tipo de sistema. A temperatura de austenitização foi de $900{ }^{\circ} \mathrm{C}$, tendo em vista que a temperatura de austenitização deste aço é de $880^{\circ} \mathrm{C}$. Já a temperatura de revenimento para este aço objetivando o grau L80 de acordo com a API5CT deve ser entre $610^{\circ} \mathrm{Ca}$ $650^{\circ} \mathrm{C}$, por isto escolheu-se a temperatura de $620^{\circ} \mathrm{C}$ neste estudo. A diferença entre os tratamentos TT_ 4 e TT_ 5 é o tempo de revenimento. No TT_ 4 a amostra foi submetida

Tabela 2. Composição química nominal da liga inconel 625 utilizada como revestimento (\% em peso)

\begin{tabular}{ccccc}
\hline $\mathbf{C r}$ & $\mathbf{M o}$ & $\mathbf{N b}$ & $\mathbf{F e}$ & $\mathbf{N i}$ \\
\hline 22,0 & 9,0 & 4,0 & 3,0 & balanço \\
\hline
\end{tabular}

Tabela I. Composição química medida do aço utilizado como substrato (\% em peso)

\begin{tabular}{ccccccccccc}
\hline $\mathbf{C}$ & $\mathbf{M n}$ & $\mathbf{S i}$ & $\mathbf{C r}$ & $\mathbf{N i}$ & $\mathbf{M o}$ & $\mathbf{T i}$ & $\mathbf{C u}$ & $\mathbf{B}$ & $\mathbf{A l}$ & $\mathbf{F e}$ \\
\hline 0,26 & $\mathrm{I}, 0$ & 0,15 & 0,30 & 0,02 & 0,03 & 0,04 & 0,06 & $0,00 I 5$ & 0,03 & balanço \\
\hline
\end{tabular}



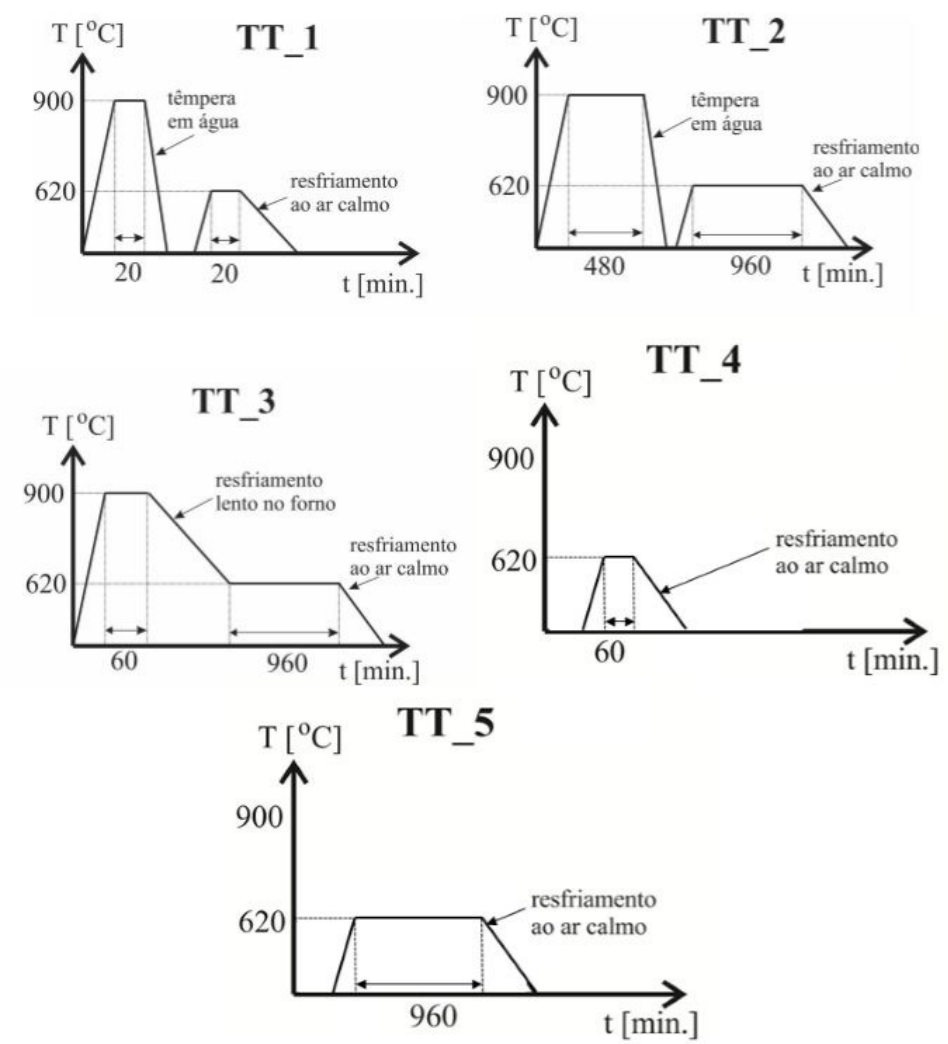

Figura I. Representação esquemática dos cinco tratamentos térmicos utilizados neste trabalho.

a temperatura de $620^{\circ} \mathrm{C}$ por 60 minutos, enquanto no TT_5, por 960 minutos.

Amostras do estado de entrega e termicamente tratadas foram submetidos a uma sequência padrão de procedimentos para preparação metalográfica com lixa até $1500 \#$ seguido de polimento em pasta de diamande de $I \mu \mathrm{m}$, sem ataque químico. Após esta preparação, as amostras foram submetidas a ensaios de microdureza Vickers com carga de I kgf durante IOs e espaçamento de $0, I \mathrm{~mm}$ entre cada indentação. A incerteza das medidas é de $2 \mathrm{HVI}$. Em seguida, o aço no qual a liga foi depositada (substrato), foi atacado com Nital $2 \%$ e uma solução de éter para a revelação dos grãos austeníticos prévios que tiveram seus tamanhos medidos pelo método dos interceptos ( $50 \mathrm{~mL}$ de éter, $80 \mathrm{~mL}$ de água destilada, 2 gotas de $\mathrm{HCl}$, 3 gramas de ácido pícrico e $25 \mathrm{~mL}$ de detergente neutro). A liga inconel foi atacada eletroliticamente (corrente $2 \mathrm{~A} \mathrm{e}$ voltagem IOV) com uma solução de $10 \%$ de ácido oxálico $\left(\mathrm{C}_{2} \mathrm{H}_{2} \mathrm{O}_{4} \cdot 2 \mathrm{H}_{2} \mathrm{O}\right)$. Com os corpos de prova já atacados, estes foram caracterizados por meio das técnicas de microscopia óptica e eletrônica de varredura com EDS.

\section{RESULTADOS E DISCUSSÃO}

O aço utilizado apresenta uma boa temperabilidade como mostra a Figura 2. Esta boa temperabilidade é conferida pelo carbono associado ao considerável teor de $\mathrm{Mn}$, mas principalmente pela adição de Ti/B que confere uma boa profundidade de têmpera durante resfriamento em água.

A obtenção do grau L80 tipo I requer o tratamento térmico de têmpera e revenimento deste aço na linha industrial. A Figura 3 mostra a microestrutura típica deste aço antes da deposição do revestimento de Inconel 625 , que é majoritariamente composta de martensita revenida, mostrando a precipitação dos carbonetos de ferro decorrente do revenimento do aço na linha industrial. Os carbonetos se apresentam como pontos claros na Figura $3 b$.

A Figura 4 é uma imagem de MEV que mostra o revestimento depositado sobre o aço e os perfis de concentração dos principais elementos químicos envolvidos, medidos por EDS. Pode-se observar que as concentrações dos elementos Ni e Mo, majoritários no revestimento, são aproximadamente constantes por uma extensão média de $2,5 \mathrm{~mm}$, onde elas diminuem bruscamente, dando lugar a um aumento expressivo do teor de Fe, majoritário no aço. Esta observação permite concluir que a espessura média do revestimento, que se apresenta homogêneo, é de $2,5 \mathrm{~mm}$ e que a região de diluição (onde há difusão de Fe para a liga e Ni e Mo para o aço) é muito pequena, não chegando a $50 \mu \mathrm{m}$.

A microestrutura do revestimento no estado como depositado é uma estrutura dendrítica alinhada no sentido de extração de calor como mostrado nas Figuras $5 a$ e $5 b$ com a formação majoritária de carbonetos de $\mathrm{Mo} / \mathrm{Nb}$ entre as dendritas. As Figuras $5 c$ e $5 d$ apresentam perfis 
Trindade et al.

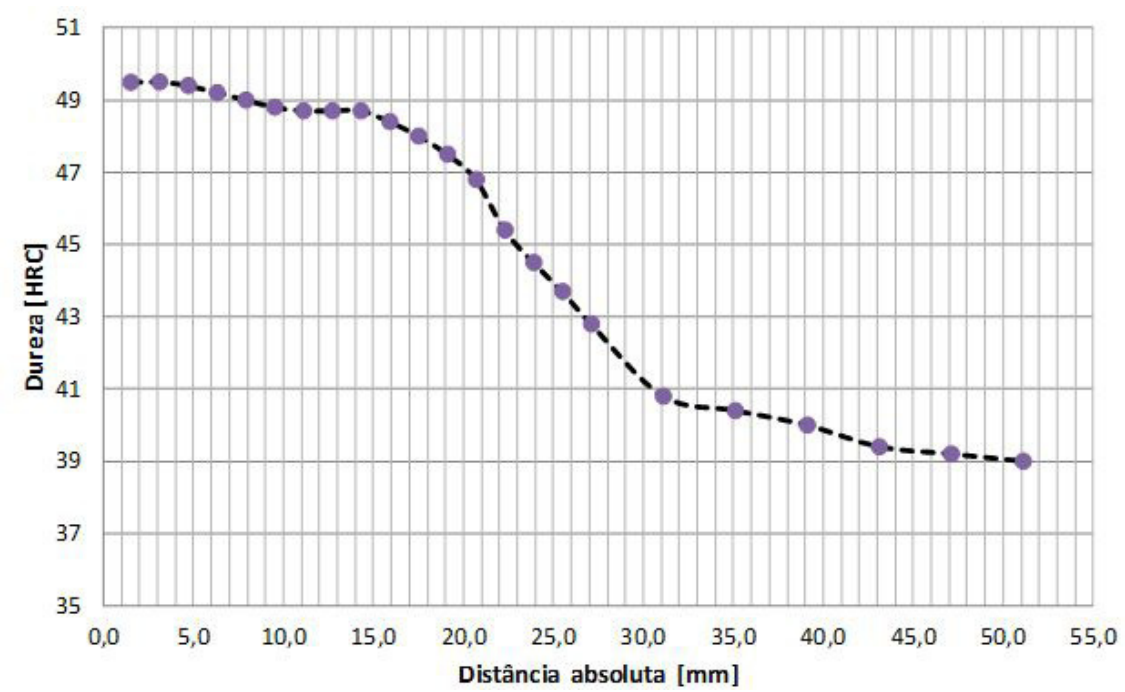

Figura 2. Curva de temperabilidade obtida pelo ensaio Jominy do aço utilizado neste estudo.

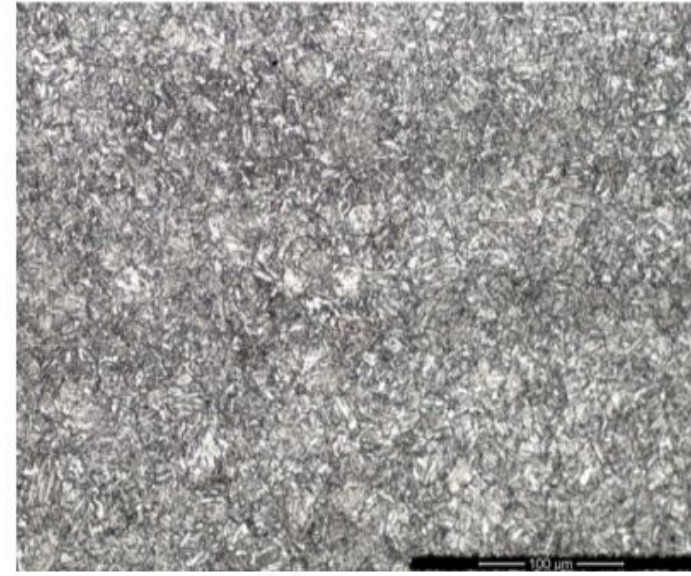

(a)

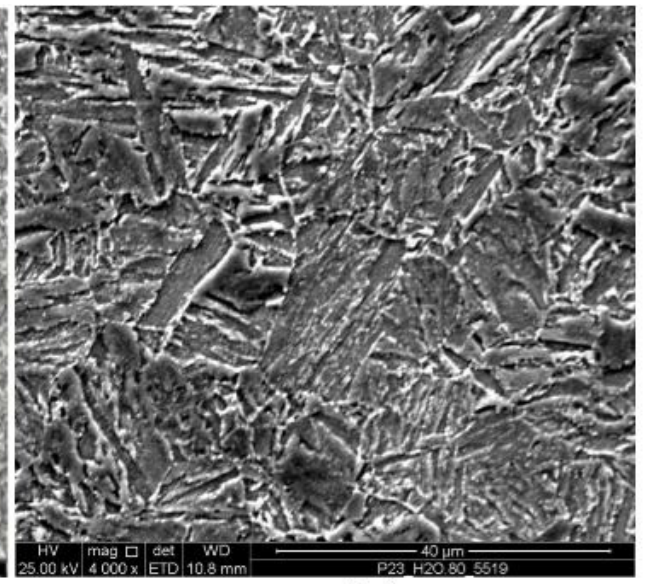

(b)

Figura 3. Microestrutura do aço usando o ataque com a solução de nital 2\%. (a) microscopia ótica; e (b) microscopia eletrônica de varredura - MEV, os pontos claros são os carbonetos, majoritariamente $\mathrm{Fe}_{3} \mathrm{C}$.

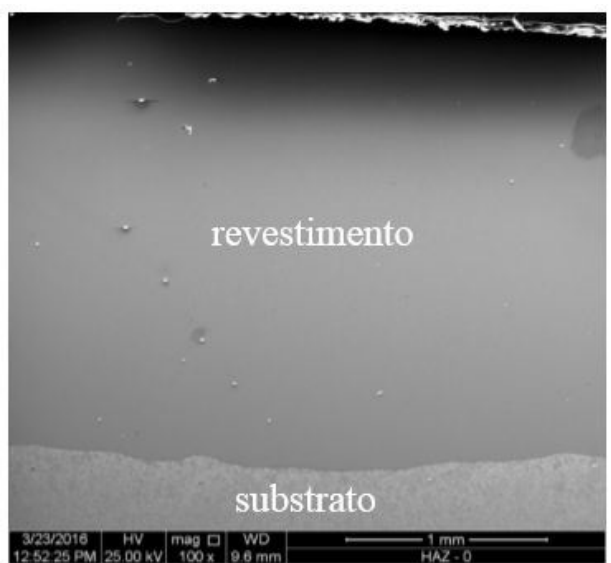

(a)

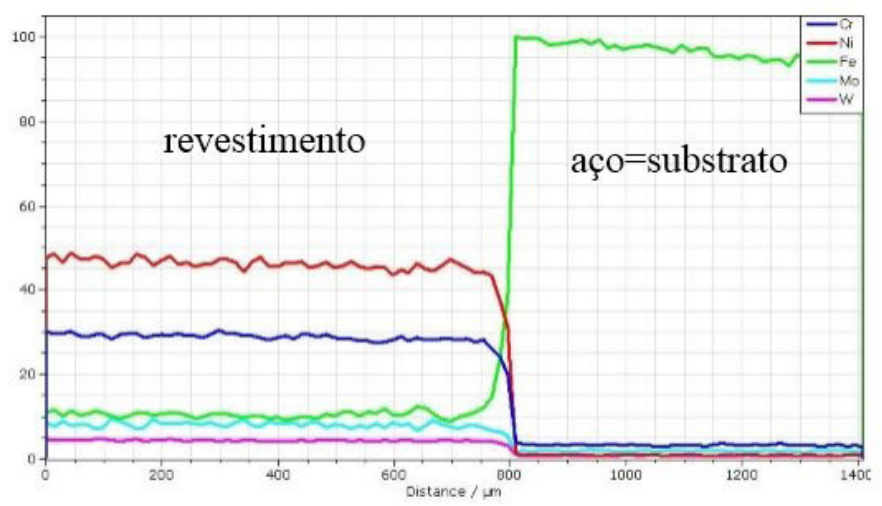

(b)

Figura 4. (a) Microestrutura sistema revestimento/aço; e (b) Perfil de composição química dada em intensidade de Raios-X característicos, dos principais elementos químicos envolvidos usando EDS. 


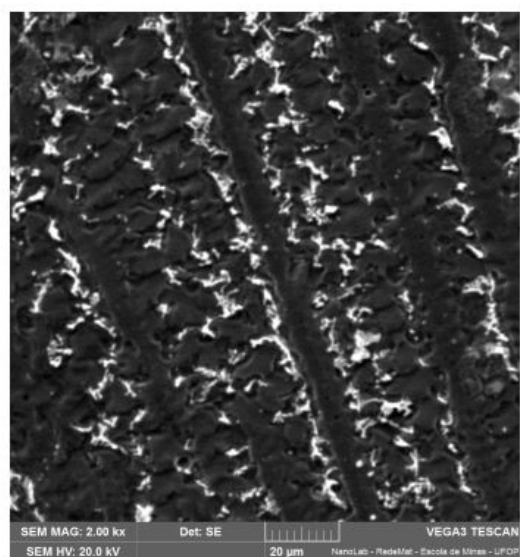

(a)

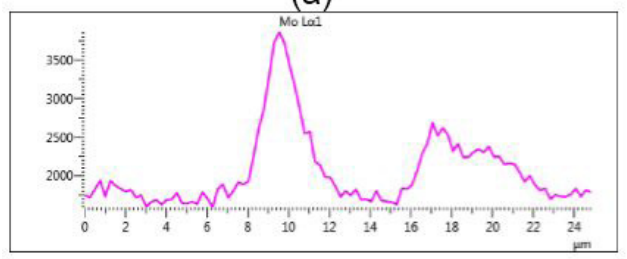

(c)

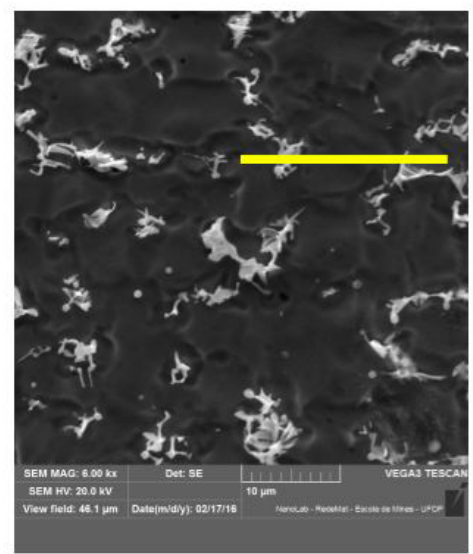

(b)

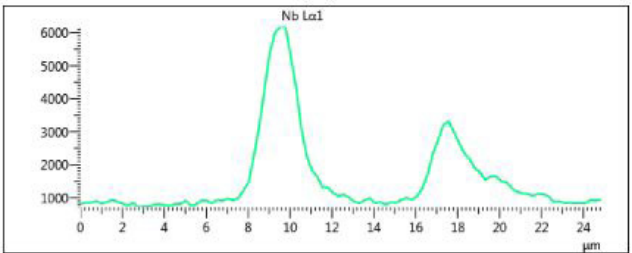

(d)

Figura 5. Microestrutura do revestimento. (a) mostrando estrutura colunar das dendritas com carbonetos entre elas; (b) aumento de 6.000x mostrando a posição da linha de EDS; (c) perfil do Mo usando EDS; e (d) perfil do Nb usando EDS.

linescan de EDS da linha em amarelo apresentada na Figura 5b. Pode-se observar que a intensidade de contagens associadas ao Mo e ao $\mathrm{Nb}$ aumentam significativamente nas posições onde se encontram os carbonetos interdendríticos (partículas brancas sob elétrons secundários). Este resultado associado a dados apresentados previamente na literatura técnica $[7,8,10,16,17]$, corroboram para a afirmação a respeito da presença majoritária dos carbonetos de Mo e Nb.

Pelo perfil da microdureza mostrado na Figura 6, pode-se observar três regiões com diferentes valores de microdureza. $O$ revestimento tem uma microdureza média de $230 \mathrm{HVI}$ uma zona termicamente afetada (ZTA) com microdureza máxima de $453 \mathrm{HVI}$ e do substrato não afetado termicamente pelo calor de $220 \mathrm{HVI}$. A incerteza das medidas é de $\pm 2 \mathrm{HVI}$.

A microdureza homogênea do revestimento é consequência de uma microestrutura homogênea constituída por dendritas de uma solução sólida onde o Ni é o solvente com precipitação acentuada de carbonetos. No aço, a formação de uma zona termicamente afetada (ZTA) com alta dureza se deve à formação de bainita. Esta região do aço teria sido austenitizada com baixa temperatura de austenitização durante a deposição a laser, e, durante o resfriamento, teria dado origem a uma estrutura bainítica muito refinada, de elevada dureza. A Figura 7 apresenta a microestrutura bainítica formada na ZTA do substrato.

Após os cinco tratamentos térmicos vários fenômenos ocorreram, tanto no revestimento, na ZTA e na região do substrato que não foi afetado pelo ciclo térmico da deposição do revestimento. A Figura 8 mostra os perfis de microdureza antes e após os tratamentos térmicos.

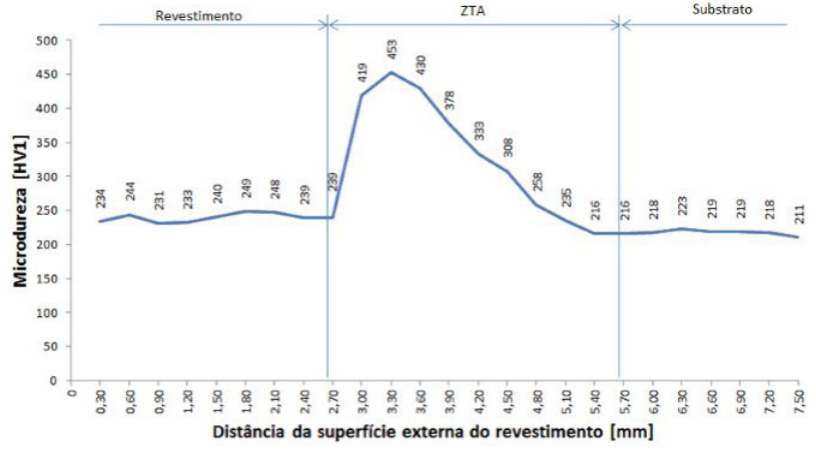

Figura 6. Perfil de microdureza ao longo da seção transversal do sistema revestimento/aço.

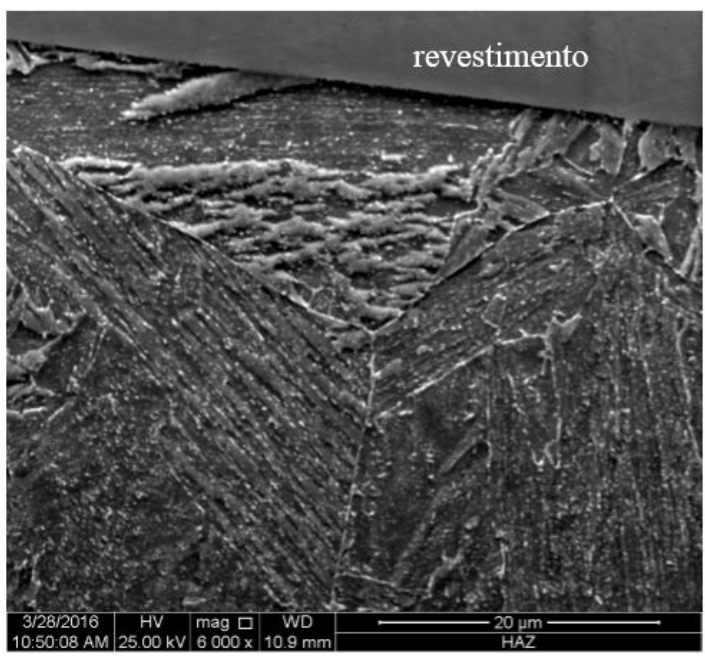

Figura 7. Formação de bainita na ZTA do aço. 


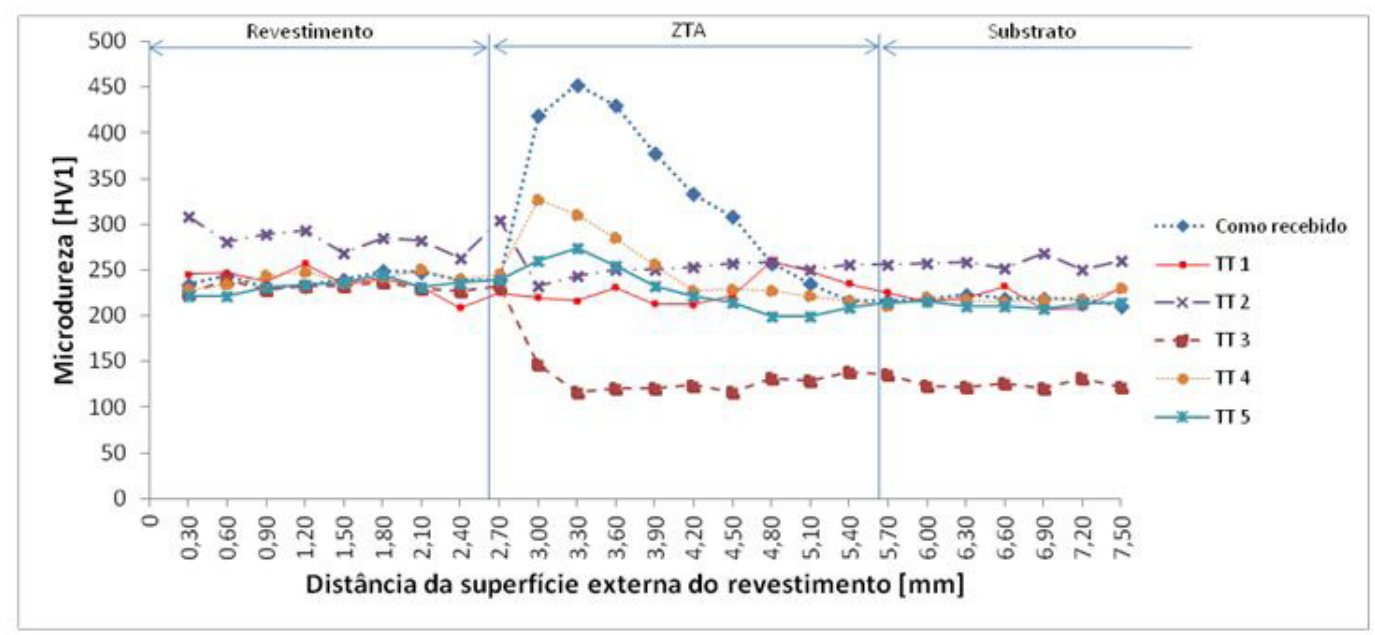

Figura 8. Perfil de microdureza no estado como recebido (depositado) e após os cinco diferentes tratamentos térmicos.

O tratamento TT_I mostra que a microdureza do revestimento não sofreu alteração, isto está de acordo com a literatura, pois apesar da fase $\delta\left(\mathrm{Ni}_{3} \mathrm{Nb}\right)$ ser termodinamicamente estável a $900{ }^{\circ} \mathrm{C}$ sua formação necessita de tempo e 20 minutos não é suficiente para este processo difusional [16-18]. A parte do substrato que não foi afetada termicamente pelo ciclo térmico da deposição também não sofreu alteração da dureza após TT_ I, pois o ciclo térmico TT_I foi idêntico ao ciclo térmico no estado como recebido. No entanto, a região afetada pelo ciclo térmico da deposição (ZTA) sofreu grande redução da dureza (de $453 \mathrm{HVI}$ para $230 \mathrm{HVI}$ ). Isto foi devido ao fato de que a bainita formada na ZTA durante a deposição foi completamente austenitizada durante TT_I e martensita revenida foi formada após têmpera e revenimento.

O tratamento TT_2 mostra que a microdureza do revestimento aumentou em média $30 \mathrm{HVI}$ em relação ao estado como recebido (como depositado). Esta elevação da microdureza após TT_2 está de acordo com a literatura, pois a $900{ }^{\circ} \mathrm{C}$ a fase $\delta$ é estável termodinamicamente e o tempo de 8 horas é longo o suficiente para a sua formação, que segundo a literatura são finas lamelas (em média $100 \mu \mathrm{m}$ de comprimento por I $\mu \mathrm{m}$ de espessura) $[16,17]$. Resultados semelhantes de elevação de dureza após tratamento térmico em condições similares a estas foi observado por outros autores $[16,17]$. A microdureza da ZTA reduziu significativamente, pela ocorrência do mesmo fenômeno já mencionado no TT_I. Por ouro lado a microdureza do substrato sofreu uma elevação da microdureza em comparação ao estado como recebido. Do ponto de vista do longo tempo no revenimento, era de se esperar uma redução da microdureza após TT 2, devido à maior quantidade de carbono que poderia difundir para fora da rede da martensita. No entanto, apesar deste fenômeno ter provavelmente acontecido a microdureza não reduziu, e sim aumentou em média $25 \mathrm{HVI}$, isto porque, o tempo de austenitização também foi muito longo (8h), o que causou crescimento de grão da austenita (tamanho médio de grão da austenita no estado como recebido foi de $14 \mu \mathrm{m}$ e tamanho de grão da austenita após TT_2 foi de $21 \mu \mathrm{m}$ ), o que segundo estudos [19-2I], acarreta em elevação da temperabilidade do aço, bem como muda a morfologia da martensita com consequente influência nas suas propriedades, dentre elas a microdureza.

O tratamento TT_3 mostra que o perfil de microdureza do revestimento não sofreu nenhuma considerável alteração devido ao curto tempo a $900^{\circ} \mathrm{C}$. Por outro lado, a microdureza da ZTA e do substrato sofreram uma forte redução causada pelo resfriamento lento no forno após austenitização, causando a formação de ferrita + perlita.

O tratamento TT_4 mostra que a microdureza do revestimento não é afetada, assim como a microdureza do substrato que também não sofre nenhuma modificação, mesmo com revenimento de I h que é superior ao tempo de revenimento no estado como recebido que foi de 20 minutos. Por outro lado, a microdureza da ZTA sofreu uma redução significativa causada pelo "revenimento" da bainita, ou seja coalescimento dos carbonetos $\left(\mathrm{Fe}_{3} \mathrm{C}\right)$.

O tratamento TT_5 mostra que a microdureza do substrato é praticamente igual ao estado como recebido, mas apresenta uma tendência à redução da dureza devido ao longo tempo de revenimento. Por outro lado, a microdureza da ZTA reduz significativamente, mostrando a influência do tempo de revenimento dos processos difusionais do carbono na bainita causando coalescimento dos carbonetos.

Para o contexto de aplicação deste recobrimento em paredes internas de tubulações, a principal característica buscada é uma boa resistência à corrosão. Entretanto, como estes tubos operam constantemente em condições de carregamento dinâmico, eles estão sujeitos ao fenômeno de fadiga. Neste sentido, a variação brusca de dureza na ZTA do substrato, causada pelo processo de deposição a laser da liga inconel não é desejável, pois esta variação acentuada de propriedades em uma extensão tão curta favorece o 
fenômeno de fadiga de contato, onde trincas podem nuclear preferencialmente por fadiga na região de baixa dureza da parede, depois da ZTA, o que pode promover o arrancamento da camada de inconel com o tempo de serviço, deixando o aço exposto às condições corrosivas.

Neste sentido pode-se considerar que os melhores tratamentos são aqueles que diminuem o gradiente de dureza entre a liga depositada, ZTA e substrato, que no presente estudo foram os tratametos TT_I e TT_5.

\section{CONCLUSÕES}

A partir deste estudo, as seguintes conclusões podem ser citadas:

I. O aço usado como substrato apresenta boa temperabidade conferida pela presença de Ti/B na composição química. Ensaios de temperabilidade Jominy confirmam esta importante características de aços C-Mn usados de acordo com a norma API 5CT.
2. Após deposição de Inconel 625 sob o aço foi observada uma zona mais dura que o revestimento e $\circ$ aço original, chamada de ZTA, causada pela formação de bainita.

3. A microestrutura do revestimento como depositado apresentou dentritas colunares na direção de extração de calor com carbonetos de Mo e Nb entre as dendritas. Uma fina zona de diluição enriquecida em Ferro foi observada na interface revestimento/aço.

4. Dentre os 5 tratamentos térmicos realizados, os mais promissores em termos de performance foi o TT_I e TT_5, devido à manutenção das características originais do substrato e do revestimento e eliminação da zona dura (ZTA). O tratamento TT 2 modificou as propriedades originais do substrato e do revestimento. O tratamento TT 3 deteriorou completamente a microestrutura e dureza do aço, devido à formação de ferrita + perlita. Já o tratamento TT_4 não foi capaz de eliminar completamente a zona dura (ZTA).

\section{REFERÊNCIAS}

I Joosten MW. Corrosion of carbon steels by $\mathrm{H}_{2} \mathrm{~S}$ in $\mathrm{CO}_{2}$ containing oilfield environments; 10 year update. In: Nace Corrosion Conference; 2015. 2015.

2 Lin T., Zhang Q., Lian Z., Liu Y. Evaluation of casing integrity defects considering wear and corrosion: application to casing design. Journal of Natural Gas Science and Engineering, 20I6;29:440-452.

3 Gao D., Sun L., Lian J. Prediction of casing wear in extended-reach drilling. Petroleum Science. 20 I0;7(4):494-50I.

4 Rodriguez MALH, Delgado DIM, Gonzalez JR, Rodriguez J. Corrosive wear failure analysis of a material gas pipeline. Wear. 2007;263(I-6):567-57I.

5 Kaldal GS, Jonsson M, Palsson H, Karlsdottir SN. Structural modeling of the casings in high temperature geothermal wells. Geothermics. 20I5;55:126-I37.

6 Zeng Y, Guzonas D. Corrosion assessment of candidate materials for fuel cladding in Canadien SCWR. Journal of the Minerals Metals \& Materials Society. 2015;68(2):475-479.

7 Borgstedt H. U. Das Korrosionsverhalten der Nickelbasislegierung Inconel 625. Materials and Corrosion. 1966; I7(12): 1027-1033.

8 Dinda GP, Dasgupta AK, Mazumder J. Laser aided direct metal deposition of inconel 625 superalloy: microstructural evolution and thermal stability. Materials Science and Engineering A. 2009;509(I-2):98-104. http://dx.doi. org/10.1016/j.msea.2009.01.009.

9 Pajukoski H, Nakki J, Thieme S, Tuominen J, Nowotny S, Vuoristo P. High performance corrosion resistant coatings by novel coaxial cold- and hot- wire laser cladding methods. Journal of Laser Applications. 2016;28: I.

10 Pontarrollo A, Vezzu S, Trentin A, Rech S, Guidolin M, Cafissi A, et al. Characterisation of Inconel 625 coatings deposited by cold spray. In: International Thermal Spray Conference; 20I I; Hamburg, Germany. 201 I.

II Michiels J. Characterization and optimization of laser cladding inconel 625 alloy on A36 structural steel [dissertação de mestrado]. Illinois: Institute of Technology; 2006.

12 Abioye TE, McCartney DG, Clare AT. Laser cladding of Inconel 625 wire for corrosion protection. Journal of Materials Processing Technology. 2016;217;232-240.

I3 Rajania HRZ, Mousavia SAAAFM. Sani, Comparison of corrosion behavior between fusion cladded and explosive cladded inconel 625/plain carbon steel bimetal plates. Materials \& Design. 20I2;43:467-474.

14 American Society for Metals - ASM. Metals Handbook: welding, brazing and soldering. 9. ed. Ohio: Metals Park; 1983. vol. 6. 
15 American Petroleum Institute - API. API 5CT: specification for casing and tubing. $201 \mathrm{I}$.

16 Shuai L, Quingsong W, Zicheng Z. Microestructure characteristics of Inconel 625 superally manufactured by selective laser melting . Journal of Materials Science and Technology. 2015;3 I(9):I-7.

17 Fujia X, Yaohui L, Yuxin L, Binshi X, Peng H. Effect of heat treatment on microstructure and mechanical properties of Inconel 625 alloy fabricated by pulsed plasma arc deposition. Physics Procedia. 201 3;50:48-54. http://dx.doi. org/10.1016/j.phpro.2013.11.010.

18 Xing X, Di X, Wang B. The effect of post-weld heat treatment temperature on the microstructure of Inconel 625 deposited metal. Journal of Alloys and Compounds. 2014;593:1 I0-I I6. http://dx.doi.org/10.1016/j. jallcom.20I3.12.224.

19 Xueda L, Cheng JS. Influence of prior austenite grain size on martensite-austenite constituent and toughness in the heat affected zone of $700 \mathrm{MPa}$ high strength linepipe steel. Materials Science and Engineering A. 2014;616:14I-I47. http://dx.doi.org/10.1016/j.msea.2014.07.100.

$20 \mathrm{Ma} \mathrm{L}$, Maoqui W, Xu SQ, Dong HB. Austenite grain size and hardenability of Nb-B microalloyed gear steels. Transactions of Materials and Heat Treatment. 2009;30(5):74-78.

2I Yunan P, Jasmawati M, Kasni S. Effect of prior austenite grain size on the morphology and mechanical properties of martensite in medium carbon steel. Journal of Materials Science and Technology. 20 I2;28(5):46 I-466.

Recebido em: 6 Jun. 2016

Aceito em: 3 Out. 2016 